\title{
BMJ Open Traumatic spinal injuries in Saudi Arabia: a retrospective single-centre medical record review
}

\author{
Mohammad O Alawad (D) , ${ }^{1}$ Nasser Alenezi, ${ }^{1}$ Bander S Alrashedan, ${ }^{1}$ \\ Mohammed Alsabieh, ${ }^{2}$ Abdulrahman Alnasser, ${ }^{1}$ Rizwan Suliankatchi Abdulkader, ${ }^{3}$ \\ Saad Surur ${ }^{1}$
}

To cite: Alawad MO, Alenezi N, Alrashedan BS, et al. Traumatic spinal injuries in Saudi Arabia: a retrospective single-centre medical record review. BMJ Open 2020;10:e039768. doi:10.1136/ bmjopen-2020-039768

- Prepublication history for this paper is available online. To view these files, please visit the journal online (http://dx.doi. org/10.1136/bmjopen-2020039768).

Received 02 May 2020 Revised 14 September 2020 Accepted 30 October 2020

Check for updates

(c) Author(s) (or their employer(s)) 2020. Re-use permitted under CC BY-NC. No commercial re-use. See rights and permissions. Published by BMJ.

${ }^{1}$ Department of Orthopaedic Surgery, King Saud Medical City, Riyadh, Saudi Arabia

${ }^{2}$ College of Medicine, King

Saud University, Riyadh, Riyadh Province, Saudi Arabia

${ }^{3}$ Department of Public Health, Ministry of Health, Riyadh, Saudi Arabia

Correspondence to Dr Mohammad 0 Alawad; mooalawad@moh.gov.sa

\section{ABSTRACT}

Objectives To describe the patterns and outcomes of traumatic spinal injuries (TSIs) in a tertiary care trauma centre in Riyadh, Saudi Arabia.

Design Retrospective medical record review.

Setting Level 1 trauma centre for all patients presented from 1 February 2016 to 31 December 2018.

Participants and data Records of patients presenting with any spinal trauma were reviewed, and the data obtained included age, gender, nationality (as Saudi and non-Saudi), date of presentation, site of fracture/injury, associated injuries, mechanism of injury, presence of neurological involvement and hospital mortality.

Main outcomes Frequencies of different types of TSI across various subgroups.

Results We identified 692 patients who presented with TSI throughout the study period. The mean age was 36.9 years. Males represented $83.2 \%(n=576)$ of the sample size, and the most common mechanism of injury was motor vehicle collision (MVC), accounting for $66.8 \%$ of cases ( $n=462)$, while fall-related injuries were seen in $31.6 \%$ of cases $(n=219)$. A total of $454(65.6 \%)$ of all patients were Saudi, and $332(73.1 \%)$ of the TSIs in Saudis were due to MVC. Non-Saudi cases accounted for 238 (34.4\%) of all patients, and $89(37.4 \%)$ of the non-Saudi injuries were due to falls from height, and this association was statistically significant $(p<0.001)$.

Conclusion TSI was not thoroughly examined in Saudi Arabia; therefore, this study is considered the first to be done in the Kingdom using a representative sample. The fact that non-Saudi patients had a higher proportion of falls as a mechanism of injury should be taken into consideration in terms of raising awareness and taking more safety precautions, as most construction workers tend to be expatriates.

\section{INTRODUCTION}

Traumatic spinal injuries (TSIs) can result from any injury to the bony structure throughout the spinal column or its surrounding ligaments. TSIs often lead to devastating outcomes, and their burden on both patient quality of life and healthcare systems is well recognised worldwide. A systematic review found that the incidence of TSI globally is approximately 10.5 per

\section{Strengths and limitations of this study}

- This is the first epidemiological study concerning traumatic spinal injuries in the Kingdom of Saudi Arabia.

- The presence of a different subgroup of patients added value to the study (ie, finding concerning nonSaudi patients).

- The lack of previous studies in the region made it difficult to compare the findings to others.

100000 people; the mortality rate in the injured reaches up to $60 \%$ globally, and the mean mortality rate is $15.4 \%$ in high-income countries. ${ }^{1}$

Motor vehicle collisions (MVCs) have been considered the leading cause of TSI, accounting for approximately $39.5 \%$ of all cases $(\mathrm{SD} \pm 16.6) .^{2}$ According to the World Bank and the WHO, the mortality rate of MVC in Saudi Arabia reached 28.8 per 100000 people in 2016, with a worldwide rate of approximately 18 per 100000 people. $^{3}$ Notably, when compared with other mechanisms of injury, TSIs caused by MVCs showed the highest morbidity and mortality rates. ${ }^{4}$

Globally, the mean age of patients with TSI was 39.8 years $(\mathrm{SD} \pm 12.2)$. However, after considering the level of income, countries with low-medium income showed a younger mean age at the time of injury. The majority of previously reported patients with TSI were men, with a worldwide male-to-female mean ratio of $3.37 .^{1}$

On the other hand, in osteoporotic vertebral fractures, which have been studied thoroughly among women, the overall global prevalence rates ranged between $15 \%$ and $26 \%$ in women, with a male-to-female ratio of 1 in both the European Vertebral Osteoporosis Study and Canadian Multicenter Osteoporosis Study. ${ }^{5-7}$ 
Countries such as Saudi Arabia have high mortality rates caused by MVCs, and little is known about trauma-related rates of spinal injuries and the factors influencing such injuries. Therefore, we decided to conduct a thorough review. In this study, we report the patterns and outcomes of TSI in a level 1 trauma centre in Riyadh, Saudi Arabia, and their relationships with demographic factors and mechanisms of injury.

\section{METHODS}

In this retrospective medical record review, we included all patients who presented at or were referred to the King Saud Medical City (KSMC) level 1 trauma centre, which is the largest in the country with annual emergency department visits exceeding 246000. KSMC is a tertiary hospital, which is accessible to all individuals regardless of nationality or job sector.

Medical records of patients who presented with TSI from 1 February 2016 to 31 December 2018 were reviewed after obtaining approval from the KSMC Central Institutional Review Board Committee (IRB reference H1RI11-Dec18-01). Data extracted included age, gender, nationality as Saudi or non-Saudi, date of presentation, site of fracture/injury, associated injuries, and mechanism of injury, presence of neurological involvement, and hospital mortality. Mechanism of injury was classified into fall from ground level, fall from height (defined as fall from more than $2 \mathrm{~m}$ ), MVC and assault-related injuries. The data were collected in an Excel sheet and were later analysed using SPSS software (V.21.0, IBM Corp.). Descriptive analyses were carried out in terms of frequencies and percentages for categorical variables and mean and SD for continuous variables. The level of injury was a multiple response variable. Statistical differences between groups were tested using the $\chi^{2}$ test. A $p$ value $<0.05$ was considered statistically significant. To identify which of the categories had a major contribution to a significant $\chi^{2}$ value, we examined the Pearson residuals and calculated an adjusted $p$ value for each comparison after correcting for multiple testing using the Bonferroni method.

\section{Patients and public involvement}

Patients and the public were not involved in the design of this study.

\section{RESULTS}

We identified 692 patients who presented with TSI throughout the study period from 1 February 2015 to 31 December 2018, and a total of 1310 injured vertebrae were reported. The age ranged from 6.4 to 89 years with a mean (SD) age of 36.9 (16.2) years. The majority of the study participants were male $(83.2 \%)$, belonging to the 19-39 years age group (59.4\%), and were Saudi citizens $(65.6 \%)$. Among all the mechanisms of injury, MVCs were the most common $(66.8 \%)$. Falls from height were more common $(19.2 \%)$ than falls from ground level $(12.1 \%)$, and a small percentage of injuries were due to assault $(1.6 \%)$. A statistically significant difference was found between age groups and mechanism of injury $(p<0.001)$. In younger age groups, MVC was the most common mechanism; whereas in the $\geq 60$ years group, fall from ground level was the most common mechanism. The sex of the patient was significantly associated with the mechanism of injury. Males were more likely to have been injured by MVC and fall from height, whereas females were likely to have been injured from MVCs and fall from ground level. Saudi citizens were more likely to have been injured from MVCs (73.1\%) than non-Saudi patients (54.6\%); nonSaudi patients were also more likely to have been injured due to falls from height $(37.4 \%)(\mathrm{p}<0.001)$ (table 1$)$.

In the sex versus mechanism of injury comparison, Pearson residual analysis showed that the major contributions were from MVC and fall from ground. MVC was significantly more common in males $(69.6 \%$ vs $51.7 \%$, $\mathrm{p}<0.001$ ), and falling from ground was significantly more common in females $(32.8 \%$ vs $8.0 \%, \mathrm{p}<0.001)$. Similarly, with age group, the major contribution was from MVC, which was least common in the $\geq 60$ years $(36.5 \%$, $\mathrm{p}<0.001)$, as was fall from height $(4.1 \%)$. However, fall from ground level was the most common in the $\geq 60$ years group $(58.1 \%, \mathrm{p}<0.001)$ compared with other age groups, especially the $19-39$ years group $(2.2 \%, \mathrm{p}<0.001)$. With respect to nationality, Saudis were significantly more likely to have been injured by MVC $(73.1 \%$ vs $34.4 \%$, $\mathrm{p}<0.001)$ and fall from ground $(15.2 \%$ vs $6.3 \%, \mathrm{p}<0.001)$, whereas non-Saudis were more likely to experience fall from height $(37.4 \%$ vs $10.1 \% \%, \mathrm{p}<0.001)$ (table 1$)$.

Table 2 shows that the mechanism of injury was significantly associated with only cervical-level, lumbar-level and sacral-level injuries. Among cervical cases, $79.2 \%(\mathrm{n}=141)$ were due to MVC, $11.8 \%(\mathrm{n}=21)$ were due to fall from height, $5.6 \%(\mathrm{n}=10)$ were due to fall from ground level and $3.4 \% \quad(n=6)$ were due to assault, with a statistically significant difference $(\mathrm{p}<0.001)$. Among lumbar cases, $60.3 \%(\mathrm{n}=225)$ were due to MVC, $23.9 \%(\mathrm{n}=89)$ were due to fall from height, $15 \%(\mathrm{n}=56)$ were due to ground-level falls and $0.8 \%(\mathrm{n}=3)$ were due to assault, with a statistically significant difference $(\mathrm{p}<0.001)$. Among sacral cases, the most common mechanism was MVC (48.6\%), followed by fall from height $(35.1 \%)$. When interpreting columnwise, among MVC, fall from height, and fall from ground level, the most common levels of injury were lumbar and thoracic; among assault-related injuries, the most common was cervical.

Only $20.7 \%$ of the patients experienced musculoskeletal (MSK) involvement. The most common type of MSK injury seen in this study population involved the upper limb $(81,11.7 \%)$, followed by the lower limb $(68,9.8 \%)$ and pelvis $(33,4.8 \%)$. Among occiput cases, $50 \%(\mathrm{n}=2)$ had no MSK involvement; among cervical cases, $78.1 \%$ $(\mathrm{n}=139)$ had no MSK involvement; and among lumber cases, $80.4 \%(\mathrm{n}=300)$ had no MSK involvement. Among the sacral cases, $40.5 \% \quad(\mathrm{n}=15)$ had no MSK involvement. The distribution of the type of involvement was 
Table 1 Demographics and mechanisms of injury

\begin{tabular}{|c|c|c|c|c|c|c|}
\hline \multirow{2}{*}{ Variable } & \multirow[b]{2}{*}{ Total } & \multicolumn{4}{|c|}{ Mechanism of injury } & \multirow{2}{*}{$P$ value } \\
\hline & & $\begin{array}{l}\text { Motor vehicle } \\
\text { collisions } \\
\text { No } \\
(\%) \\
\end{array}$ & $\begin{array}{l}\text { Fall from height } \\
\text { No } \\
(\%)\end{array}$ & $\begin{array}{l}\text { Fall from ground } \\
\text { level } \\
\text { No } \\
(\%) \\
\end{array}$ & $\begin{array}{l}\text { Assault-related } \\
\text { injuries } \\
\text { No } \\
(\%)\end{array}$ & \\
\hline \multicolumn{7}{|l|}{ Sex } \\
\hline \multicolumn{7}{|l|}{ Age } \\
\hline$\leq 18$ years & $44(6.4 \%)$ & $34(77.3 \%)$ & $7(15.9 \%)$ & $2(4.5 \%)$ & $1(2.3 \%)$ & $<0.001$ \\
\hline 19-39 years & $411(59.4 \%)$ & $309(75.2 \%)^{\star}$ & 88 (21.4\%) & $9(2.2 \%)^{\star}$ & $5(1.2 \%)$ & \\
\hline 40-59 years & $163(23.6 \%)$ & $92(56.4 \%)^{*}$ & 37 (22.7\%) & $30(18.4 \%)$ & $4(2.5 \%)$ & \\
\hline Non-Saudi & 238 (34.4\%) & $130(54.6 \%)^{*}$ & $89(37.4 \%)$ & $15(6.3 \%)^{*}$ & $4(1.7 \%)$ & \\
\hline Total & $692(100 \%)$ & $462(66.8 \%)$ & 135 (19.2\%) & $84(12.1 \%)$ & $11(1.6 \%)$ & \\
\hline
\end{tabular}

*Significant $p$ value in Pearson residual analysis with Bonferroni correction for multiple testing. All $p$ values $<0.001$.

significantly associated with the level of spinal injury. Cervical cases were more likely to have upper limb fractures $(13.5 \%, \mathrm{p}=0.002)$, whereas lumbar cases were more likely to have lower limb fractures $(7.2 \%, \mathrm{p}=0.018)$ and sacral cases to have pelvic fractures $(29.7 \%, \mathrm{p}<0.001)$ compared with the other levels (table 3 ).

Among the cases, a total of 6 deaths $(0.9 \%)$ and 75 $(10.8 \%)$ cases of neurological deficit were noted. As depicted in table 4 , among the cervical cases, death was seen in 4 cases $(2.2 \%, p=0.005)$ and neurological deficits in 26 cases $(14.6 \%, \mathrm{p}<0.001)$, with a statistically significant association $(\mathrm{p}<0.001)$. Additionally, $7.8 \%$ of thoracic and $6.4 \%$ of lumbar spinal injuries resulted in neurological deficits.

\section{DISCUSSION}

The aim of this study was to establish the baseline epidemiology of STI and to investigate its patterns, outcomes and associated injuries. The majority of the study cases were within the 19-39year age group with a mean age of 36.9 years, similar to several previous reports. ${ }^{14-10}$ The male-to-female ratio was 5 , which is far higher than the previously reported global ratio. ${ }^{1}$ This is explained by the fact that until 24 June 2019, women were not allowed to drive in Saudi Arabia and, therefore, had substantially lower rates of TSI, as $69.9 \%$ of male cases were caused by MVC. On the other hand, the male-to-female ratio in osteoporotic fracture reported previously is the same as our reported ratio of 1 in the advanced age group and fall from ground cases.

One major finding was the rate of fall from height among non-Saudis, which was never previously examined in the literature. In Saudi Arabia, most construction workers are non-Saudis, which can possibly explain the finding related to falls from height where non-Saudis were more likely to be injured by this mechanism than Saudis $(37.4 \%$ and $10.1 \%$, respectively). This finding is reinforced by the fact that Saudis were also more likely to

Table 2 Association between spinal level affected and mechanisms of injury $(n=692)$

\begin{tabular}{|c|c|c|c|c|c|c|}
\hline \multirow{2}{*}{ Spinal level } & \multirow[b]{2}{*}{ Total } & \multicolumn{4}{|c|}{ Mechanism of injury } & \multirow{2}{*}{$P$ value } \\
\hline & & $\begin{array}{l}\text { Motor vehicle } \\
\text { collisions }\end{array}$ & Fall from height & $\begin{array}{l}\text { Fall from ground } \\
\text { level }\end{array}$ & $\begin{array}{l}\text { Assault-related } \\
\text { injuries }\end{array}$ & \\
\hline Occiput & $4(0.6 \%)$ & $3(75.0 \%)$ & $1(25.0 \%)$ & $0(0.0 \%)$ & $0(0.0 \%)$ & 0.884 \\
\hline Cervical & $178(25.7 \%)$ & $141(79.2 \%)$ & $21(11.8 \%)$ & $10(5.6 \%)$ & $6(3.4 \%)$ & $<0.001$ \\
\hline Sacral & $37(5.3 \%)$ & $18(48.6 \%)$ & $13(35.1 \%)$ & $4(10.8 \%)$ & $2(5.4 \%)$ & 0.015 \\
\hline
\end{tabular}


Table 3 Levels of spinal injury and musculoskeletal involvement

\section{Musculoskeletal involvement}

\begin{tabular}{|c|c|c|c|c|c|c|c|c|}
\hline $\begin{array}{l}\text { Spinal } \\
\text { level }\end{array}$ & Total & $\begin{array}{l}\text { No } \\
\text { involvement }\end{array}$ & $\begin{array}{l}\text { Upper limb } \\
\text { fractures }\end{array}$ & $\begin{array}{l}\text { Lower limb } \\
\text { fractures }\end{array}$ & $\begin{array}{l}\text { Both upper } \\
\text { and lower } \\
\text { limbs } \\
\text { fractures }\end{array}$ & $\begin{array}{l}\text { Pelvic } \\
\text { fractures }\end{array}$ & $\begin{array}{l}\text { Upper and/or } \\
\text { lower limb with } \\
\text { pelvic fractures }\end{array}$ & P value \\
\hline Occiput & $4(0.6 \%)$ & 2 (50.0\%) & $1(25.0 \%)$ & $0(0.0 \%)$ & $1(25.0 \%)$ & $0(0.0 \%)$ & $0(0.0 \%)$ & 0.001 \\
\hline Cervical & 178 (25.7\%) & 139 (78.1\%) & 24 (13.5\%) & $6(3.4 \%)$ & $5(2.8 \%)$ & $2(1.1 \%)$ & $2(1.1 \%)$ & 0.002 \\
\hline Lumbar & 373 (53.9\%) & 300 (80.4\%) & 20 (5.4\%) & 27 (7.2\%) & $4(1.1 \%)$ & $10(2.7 \%)$ & $12(3.2 \%)$ & 0.018 \\
\hline Sacral & 37 (5.3\%) & $15(40.5 \%)$ & $2(5.4 \%)$ & 2 (5.4\%) & $0(0.0 \%)$ & $11(29.7 \%)$ & 7 (18.9\%) & $<0.001$ \\
\hline
\end{tabular}

Table 4 Levels of spinal injury, fatality and neurological deficits

\begin{tabular}{lclllr}
\hline & \multirow{2}{*}{$\begin{array}{l}\text { Total } \\
\text { Spinal level }\end{array}$} & No (\%) & Death & & \multicolumn{2}{l}{ Presence of neurological deficit } \\
& No (\%) & P value & & No (\%) & P value \\
\hline Occiput & $4(0.6 \%)$ & $0(0.0 \%)$ & 0.864 & $0(0.0 \%)$ & 0.548 \\
Cervical & $178(25.7 \%)$ & $4(2.2 \%)$ & 0.005 & $26(14.6 \%)$ & 0.001 \\
Thoracic & $308(44.5 \%)$ & $0(0.0 \%)$ & 0.044 & $24(7.8 \%)$ & 0.703 \\
Lumbar & $373(53.9 \%)$ & $2(0.5 \%)$ & 0.531 & $24(6.4 \%)$ & 0.062 \\
Sacral & $37(5.3 \%)$ & $1(2.7 \%)$ & 0.144 & $1(2.7 \%)$ & 0.208 \\
\hline
\end{tabular}

present with TSI caused by MVC, which was the mechanism of injury for $73.1 \%$ of Saudis.

The lumbar spine was the most commonly affected area $(53.9 \%, \mathrm{n}=373)$, followed by the thoracic $(44.5 \%, \mathrm{n}=308)$ and cervical spine $(25.7 \%, \mathrm{n}=178)$, which is in contrast to the finding by AlEissa et al, where the cervical spine was found to be the most affected area. ${ }^{11}$ The difference could be explained by the fact that in our centre, data are more representative of the overall population than a specific type of patients; the other study was conducted in Saudis with limited eligibility, lifesaving cases, and mainly in MVC victims as the National Guard Health Affairs trauma centre is located in a suburb serving drivers using the main highways. This explains the higher incidence reported in our study (692 cases in 3 years) compared with the previous study (1162 cases in 15 years).

The cervical spine was the spinal level most frequently injured by MVC, with a statistically significant association $(\mathrm{p}<0.001)$. This was also reported previously in a study by El-Faramawy et $a l .{ }^{12}$ Sacral spine fractures were caused by MVC in $48.6 \%$ of cases and by falls from height in $35.1 \%$ of cases $(p=0.015)$.

In a study on unstable sacral fractures, RodriguesPinto et al reported that $40.6 \%$ of the 32 patients had upper limb involvement, ${ }^{13}$ while only $5.4 \%$ of those with sacral fractures had some extent of upper limb injuries. Although our study did not examine the difference between levels of cervical spine injury and neurological deficits, a Scandinavian study found that subaxial injuries were more likely to have neurological deficits than $\mathrm{C} 0-\mathrm{C} 2$ injuries. ${ }^{14}$ In the afore-mentioned study, $10 \%$ of cervical spine injuries had a degree of neurological deficit, while in our study, $14.6 \%$ of the total cervical spine injury cases presented with neurological deficits.

This is the first epidemiological study concerning TSIs in the Kingdom of Saudi Arabia with an effort to include Saudi and non-Saudi populations. The findings observed in the study necessitate us to raise concern to government sectors regarding safety measures in the workplace and traffic rule adherence. Lumbar spine fractures were found to be most common, as reported in studies of Western populations. Inclusion of a different subgroup of patients was a key strength to this study (ie, findings concerning non-Saudi patients). However, the lack of previous studies in the region made it difficult to compare the findings to others. Due to the lack of a national database allowing us to more cases and their longitudinal data, we were limited to the available single-centre medical records. Future studies should focus on the impact of socioeconomic status on TSI as well as the economic burden these injuries might cause.

\section{Twitter Mohammad 0 Alawad @alawadmo}

Contributors MOA: analysis and interpretation of data and revision of the manuscript. NA: design of the study, acquisition of data and revision of the manuscript. BSA: acquisition, analysis and interpretation of data, and revision of the manuscript. AA: acquisition of data and revision of the manuscript. MA: acquisition of data and revision of the manuscript. RSA: analysis and interpretation of data and revision of the manuscript. SS: revision of the manuscript.

Funding The authors have not declared a specific grant for this research from any funding agency in the public, commercial or not-for-profit sectors.

Competing interests None declared. 
Patient and public involvement Patients and/or the public were not involved in the design, or conduct, or reporting, or dissemination plans of this research.

Patient consent for publication Not required.

Provenance and peer review Not commissioned; externally peer reviewed.

Data availability statement Data are available upon reasonable request to corresponding author.

Open access This is an open access article distributed in accordance with the Creative Commons Attribution Non Commercial (CC BY-NC 4.0) license, which permits others to distribute, remix, adapt, build upon this work non-commercially, and license their derivative works on different terms, provided the original work is properly cited, appropriate credit is given, any changes made indicated, and the use is non-commercial. See: http://creativecommons.org/licenses/by-nc/4.0/.

\section{ORCID iD}

Mohammad 0 Alawad http://orcid.org/0000-0001-6837-2159

\section{REFERENCES}

1 Kumar R, Lim J, Mekary RA, et al. Traumatic spinal injury: global epidemiology and worldwide volume. World Neurosurg 2018;113:e345-63.

2 WHO. Road traffic injuries. fact sheets. Available: https://www.who. int [Accessed 10 Oct 2019].

3 Worldbank. Mortality caused by road traffic injury(per 100,000 people). Available: https://data.worldbank.org/indicator [Accessed 10 Oct 2019].

$4 \mathrm{Al}$-Jadid MS. A retrospective study on traumatic spinal cord injury in an inpatient rehabilitation unit in central Saudi Arabia. Saudi Med $J$ 2013;34:161-5.
5 Ballane G, Cauley JA, Luckey MM, et al. Worldwide prevalence and incidence of osteoporotic vertebral fractures. Osteoporos Int 2017;28:1531-42.

6 O'Neill TW, Felsenberg D, Varlow J, et al. The prevalence of vertebral deformity in European men and women: the European vertebral osteoporosis study. J Bone Miner Res 1996;11:1010-8.

7 Jackson SA, Tenenhouse A, Robertson L. Vertebral fracture definition from population-based data: preliminary results from the Canadian multicenter osteoporosis study (CaMos). Osteoporos Int 2000;11:680-7.

8 Wang $\mathrm{H}$, Liu $\mathrm{X}$, Zhao $\mathrm{Y}$, et al. Incidence and pattern of traumatic spinal fractures and associated spinal cord injury resulting from motor vehicle collisions in China over 11 years: an observational study. Medicine 2016;95:e5220.

9 Leucht P, Fischer K, Muhr G, et al. Epidemiology of traumatic spine fractures. Injury 2009;40:166-72.

10 Alkhathlan KM, Alzahrani MG, Aldosari KH, et al. Traumatic spinal injuries in the Kingdom of Saudi Arabia: a study of associated injuries, management and mortality. Pan Afr Med J 2019;32:153.

11 AlEissa S, AIAssiri SS, AlJehani RM, et al. Neurological disability among adults following traumatic spinal fractures in Saudi Arabia: a retrospective single-center medical record review. Ann Saudi Med 2019;39:8-12.

12 El-Faramawy A, El-Menyar A, Zarour A, et al. Presentation and outcome of traumatic spinal fractures. J Emerg Trauma Shock 2012;5:316-20.

13 Rodrigues-Pinto R, Kurd MF, Schroeder GD, et al. Sacral fractures and associated injuries. Global Spine J 2017;7:609-16.

14 Fredø HL, Rizvi SAM, Lied B, et al. The epidemiology of traumatic cervical spine fractures: a prospective population study from Norway. Scand J Trauma Resusc Emerg Med 2012;20:85. 